\title{
Smertejournal
}

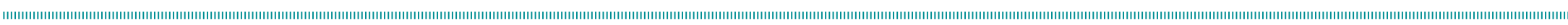
Karin Torvik, Avdeling for Helsefag og Senter for Omsorgsforskning, Midt-Norge, HiNT, Liv Kirsti L Hårstad, Åshild By Berdal, Aud Frønes, Ellen Ommedal Strøm, Marie Helleren Gunn Karlsaunet, alle ansatt i Åjord kommune og Kirsti Torjuul, Avdeling for sykepleierutdanning og Senter for Omsorgsforskning, Midt- Norge, HiNT.

\section{Kartlegger smerte}

\section{Innføring av felles smertekartleggingsverktøy i Åfjord kommune har ført til bedre smertebehandling.}

$\AA$ fjord kommune har cirka 3250 innbyggere og ligger på Fosenhalvøya i SørTrøndelag. Kommunehelsetjenesten består blant annet av legetjeneste, sykehjem, rehabiliteringstjenesten og hjemmetjeneste. Mange av kreftpasientene i kommunen har oppfølging fra kreftpoliklinikken i Rissa, og det er et godt samarbeid mellom pasient, fastlege, hjemmetjeneste, sykehjem og poliklinikken.

\section{Lindrende behandling}

Det har i flere år eksistert en tverrfaglig ressursgruppe for kreftomsorg i kommunen. Hjemmetjenesten i Åfjord ble tildelt status som utviklingssenter for hjemmetjenester i Sør-Trøndelag i august 2009. Ressursgruppen fikk da ansvar for å utvikle og kvalitetssikre lindrende behandling i kommunen. Gruppen

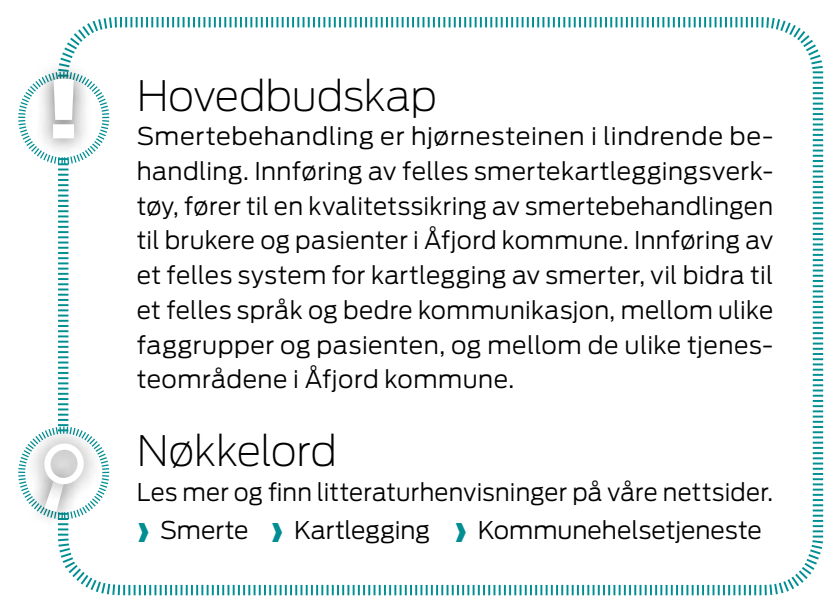

ble utviklet til en prosjektgruppe for lindrende behandling og omsorg ved livets slutt. Bakgrunnen for prosjektet var at helsearbeiderne hadde møtt mange brukere med smerte, forårsaket av kreft eller andre uhelbredelige lidelser. De så hvordan smerter i stor grad innvirket på deres hverdag og livskvalitet og ønsket derfor å gjøre noe for å lindre smertene.

\section{Smerte}

Smerte er det symptomet både pasient og pårørende frykter mest $(1,2)$. Smertebehandling er selve hjørnesteinen i lindrende behandling. Ubehandlet smerte gir mange sekundærproblemer som eksempelvis kvalme, angst, depresjon, anoreksi og søvnproblemer (2). Lykkes man ikke med smertebehandlingen, vil de fleste av disse problemer forbli uløst $(1,2)$. Vellykket smertebehandling krever systematisk, tverrfaglig tilnærming både i diagnostikk og behandling, og en anbefaler derfor bruk av standardiserte kartleggingsverktøy (1). Den optimale kartleggingen oppnås når pasienten er i stand til å rapportere sine smerter selv, da smerter er en subjektiv opplevelse $(1,2)$.

\section{Definisjon}

Smerte er definert som «en ubehagelig sensorisk og emosjonell opplevelse assosiert med aktuell eller potensiell vevskade, eller beskrevet som slik skade» (3). Smerte er både en universell og en personlig opplevelse; universell i den forstand at de fleste har en eller flere ganger opplevd smerte, personlig i den forstand at det er bare den som opplever smerte som kjenner smertens karakter og intensitet. International
Association for the Study of Pain (IASP) påpeker at smerte er et sammensatt fenomen som inneholder både en sanselig (sensorisk) og en emosjonell komponent (3). I tillegg har den en kognitiv komponent; personens evne til å forstå og tolke smerteopplevelsen (4). IASP hevder også at smerte ikke er avhengig av at personen kan uttrykke sin smerte verbalt. Smerterapportering kan være både verbal og nonverbal, og det er helsepersonellets ansvar å observere og tolke den verbale og nonverbale smerterapporteringen $(3,4)$. Det kan være mange grunner til at mennesker ikke selv kan uttrykke smerten sin verbalt, for eksempel slag- eller demenssykdom. Studier viser at 80 prosent av norske sykehjemspasienter har en demenssykdom (5).

Det beste for smertepasienten er at alle yrkesgrupper i kommunehelsetjenesten samarbeider tett om diagnostikk og behandling. Prosjektgruppen ønsket derfor å ta i bruk et instrument for smertekartlegging som skulle brukes av alle ansatte i hele kommunen. Ved å bruke det samme instrumentet på samme pasient kunne de sammenlikne og dokumentere pasientens smerte over tid.

\section{Kvalitetssikring}

Målet med prosjektet var å kvalitetssikre smertebehandlingen til brukere og pasienter i Åfjord kommune ved å innføre et felles smertekartleggingsverktøy og gjennomføre opplæring av ansatte i smerte og smertebehandling. Prosjektgruppen besto av seks helsearbeidere fra hjemmetjenesten, sykehjemmet, rehabiliteringstjenesten og legekontoret. Prosjektet 


$\begin{array}{llll}\text { Forfatter, tittel, } & \text { Hensikt / Formål } & \text { Metode } & \text { Rommentar } \\ \text { tidsskrift, år. } & & \end{array}$

Payen, Bru, Bosson, Lagrasta, Novel, Deschaux, Lavange, Jacguot. «Assessing pain in critically ill sedated patients by using a bahavioral pain scale.» Crit Care Med 2001;12:2258-2263
Kartlegging av smerter hos kritisk syke pasienter, som har fått beroligende, ved hjelp av atferdmessig smerteskala. Målet er å etablere et nytt BPS (behavioral pain scale) somer gyldig og pålitelig, for voksne pasienter som er kritisk syke. Begrunnet i at mange opplever smerter mens de er innlagt på en intensivavdeling.

Rhodee dan Herk, Monique van Diijk, Frans P. M. Baar, Dick Tibboel, Rianne de Wit. «Observation scale for pain assessment in older adults with cognitive impairments orcommunication difficulties») Nursing Research 2007;:13443.

Rodriguez, McMillan, Yarandi.

«Pain measurement in older adults with head and neck cancer and communication impairmentsı

Cancer Nursing

2004;6:425-433.
Få et overblikk over smerteskalaer som blir brukt hos eldre mennesker med kognitiv svikt, kommunikasjonsproblemer eller en kombinasjon av kognitiv svikt og kommunikasjonsproblemer.

Denne studien sammenligner effektiviteten av tre smerte-kartleggingsverktøy (NRS, Ansiktscala, VAS) for å bedømme/måle smerteintensiteten hos eldre voksne med hode/hals kreft med kommunikasjonssvekkelse (verbal).
Kvantitativ studie. Kartlegging av smerter hos 30 pasienter i respirator, som mottok smertestillende og beroligende. BPS ble vurdert ut fra ansiktsuttrykk, bevegelser i øvre kroppsdel, i samsvar med ventileringen. De ble inndelt i 3 ulike grupper ut ifra hvilke prosedyrer de skullegjennomog hvor mye beroligende og smertestillende som ble gitt (ble gitt fast $3 x$ dgl.). 6 sykepleiere og sykepleierstudenter foretok kartleggingen. 269 kartlegginger ble gjennomført.
Det er gyldig og pålitelig å bruke atferdsmessige smerteskala for å bedømme smerter hos pasienter som ligger i respirator. Smertefulle prosedyrer resulterte i betydeligere høyere BPS enn hos gruppen som ikke hadde behov for smertestillende på forhånd. Det er en sammenheng mellom dosering av beroligende/smertestillende og BPS: jo høyere dosering jo lavere BPS-resultat. BPS endres ved smertefull stimulering.
Studien bekrefter at det har en hensikt å bruke BPS hos intensivpasienter. I vårt arbeid møter vi terminale pasienter som ikke er i stand til å gi uttrykk for smerter verbalt. Da kan BPS være aktuell, hvor vi som hjelpere må kartlegge gjennom observasjon.
Litteraturstudie. Databasene PubMed, Medline, Psyclnfo, Cinal og Picarta. Søkeord: pain (measurement) and dementia or alzheimer or (aged, 80 and over/frail elderly) and communication disorders. Referanselistene til artiklene som ble hentet fram ble også gjennomsøkt. Artiklene som var aktuelle hadde brukt smerteobservasjonsskala i en empirisk studie.

Kvantitativ studie. Studiens deltakere var klar og orienterte med overnevnt diagnose (MMS over 24).
Ning Wu, Susan C. Miller, Kate Lapane, Jacon Roy, Vincent Mor. «Impact of cognitive function on assessments of nursing home residents pain»" Medical Care 2005; 9:934-939
Å undersøke hvilken innvirkning sykehjemsbeboernes kognitive funksjon har på kvaliteten av Minimum Data Set (MDS) smertedata.

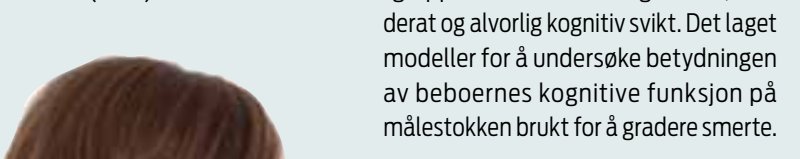

Kvantitativ studie. 3736 sykehjemsbeboere fordelt på 209 sykehjem ble vurdert av sykehjemsansatte og opplærte sykepleiestudenter. De ble oppdelt i grupper: beboere med ingen/lett, moderat og alvorlig kognitiv svikt. Det laget modeller for å undersøke betydningen målestokken brukt for å gradere smerte.

13 forskjellige smerteobservasjonsskalaer ble utvalgt. Ansiktsuttrykk, lyd, kroppsspråk, væremåte og humør er kategorier som ble presentert i de fleste studiene. De fleste studiene ble vurdert som for begrenset og uferdige til å kunne brukes i klinisk praksis. De mest aktuelle observasjonsskalaene som det bør forskes videre på er: FACS, DSDAT, PAINAD, og PACSLAC.

Funnene i denne studien viser at både FPS (ansiktskala), NRS og VAS er gyldige/gode for å kartlegge smerter hos voksne med hode-/ halskreft med verbal kommunikasjonssvikt. Studiens funn gir tillit til å bruke disse verktøyene. Selvrapportering av smerte er mulig ved kommunikasjonssvikt ved hode-/halskreft. Deltakerne av studien foretrakk NRS for å måle smerteintensitet.

40,4 \% ingen/mild, 35,9\% moderat, 23,7\% alvorlig kognitiv svekkelse. Både ansatte på sykehjem og sykepleierstudenter registrerte mindre hyppige og mindre sterke smerter for beboere med mer alvorlig kognitiv svikt. Deansattes og studentenes kartlegging samsvarte godt. Litteraturen antyder at smerterelaterte forhold er felles hos alle og at smerte er undervurdert hos beboere med kognitiv svikt.
Aktuell artikkel for oss. Studien er foretatt i en bestemt diagnose gruppe, men anvendelse av verktøyet må være mulig ved smerter hos pasienter med andre diagnoser.
Vi ønsker å forbedre smertekartlegging. Denne artikkelen tyder på at det er nødvendig. Det er viktig med god smertebehandling uavhengig av kognitiv funksjon. 
besto av litteratursøk for å velge smertekartleggingsverktøy, utprøving av felles kartleggingsverktøy i kommunen og undervisning for alle ansatte om smerte og smertebehandling.

\section{Litteratursøk}

Prosjektgruppen valgte først å gjennomføre en allmenn litteraturstudie (6) og søkte i databasene Svemed og Medline med tilgang fra Helsebiblioteket. Gruppen fant 11 aktuelle forskningsartikler som ble fordelt mellom deltakerne i prosjektgruppen og vurdert med hensyn til om smertekartleggingsverktøyet var klinisk relevant for bruk i Åfjord kommune. (Se tabell 1). Etter gransking av artiklene, satt vi igjen med følgende kartleggingsskjemaer som vi ønsket å undersøke nærmere:

I Smertekart/smertejournal og Edmonton symptom assessment system (ESAS)

, Verbalskala

, Doloplus 2

> Mobilization observation behavior intensity dementia (MOBID 2)

> Pain assessment in advanced dementia (PAINAID)

I Behavioural pain scale (BPS)

, Checklist of nonverbal pain indicators (CNPI)

\section{«Smerte er en subjektiv opplevelse.»}

Våren 2011 hadde prosjektgruppen valgt ut to kartleggingsverktøy som de ønsket å prøve på pasienter med smerte i kommunen: Smertejournal/ESAS $(7,8)$ til pasienter som selv kan rapportere smerte og Doloplus-2 $(4,9,10)$ til pasienter som ikke selv kan rapportere smerte. Det ble gitt opplæring i bruk av disse kartleggingsverktøyene til alle helsearbeiderne i kommunen.

\section{Informasjon og opplæring}

Gruppen informerte alle helsearbeidere og ledere i kommunen om prosjektet. Det ble særlig vektlagt å informere ansatte ved sykehjemmet, i hjemmetjenesten og legene i kommunen, da det var disse gruppene som hadde ansvar for smertekartlegging av pasientene. Videre ble det arrangert en fagdag med temaet smerte og helhetlig smertebehandling i 2010. Forelesere var medlemmer av prosjektgruppen, diakon i kommunen, leger og sykepleier ved Fosen Kreftpoliklinikk og en forsker på smerte hos eldre, ansatt ved Senter for Omsorgsforskning,
Midt-Norge. Helsearbeidere fra hele Fosen ble invitert og deltok på fagdagen. I januar 2012 fikk alle helsearbeiderne internundervisning om smertebehandling. Denne undervisningen ble gjennomført av tilsynslegen ved sykehjemmet.

\section{Resultater og drøfting}

Pasienter som selv kan rapportere smerte

Til denne pasientgruppen ønsket vi å teste ut ESAS og smertejournal utarbeidet ved universitetssykehuset i Nord-Norge (UNN). En studie viste at nummerskala (NRS) var valid for å kartlegge smerter hos voksne med kreft i hode-/ eller halsregion (11). Studien ble gjennomført i en diagnosegruppe; voksne med kreft i hode-/ halsregion. Vi mente at nummerskalaen (NRS) kunne anvendes til voksne palliative pasienter, fordi diagnosen ikke nødvendigvis har sammenheng med personens evne til å tallfeste smerteintensitet. Rundt årsskifte 2011/2012 kom den norske oversettelsen av ESAS-r. Prosjektgruppa ønsket imidlertid å gjennomføre prosjektet med ESAS og bytte til ESAS-r når prosjektet ble avsluttet og kartleggingsverktøyene eventuelt skulle implementeres i ordinær drift.

ESAS kartlegger flere symptomer enn smerte: slapphet, døsighet, kvalme, matlyst, tung pust, depresjon, angst og velvære. Dette er symptomer som henger sammen med smerte, spesielt hos pasienter i en palliativ fase (2). Kartleggingsskjemaet har også vist seg å være et godt redskap for kommunikasjon mellom helsepersonell og pasient og kan benyttes for alle pasienter med langtkommet sykdom og som har evne til selv å rapportere smerte (8). ESAS og ESAS$r$ brukes flere steder i landet og Norsk forening for palliativ medisin har tatt initiativ til at ESAS-registrering skal innføres som standard i lindrende behandling i Norge.

Smertejournal med kroppskart utviklet ved Universitetet i Nord-Norge (7) ble valgt fordi den var rask å bruke samtidig som den kartla andre områder enn ESAS. Smertejournal kartla i tillegg hvordan smerten ble opplevd, hva som forårsaket og lindret smerten, variasjon gjennom døgnet samt smertens påvirkning på andre områder som for eksempel søvn og smertelokalisering.

Pasienter som ikke kan rapportere smerte selv

Til pasientgruppen som ikke kan rapportere selv ønsket vi å prøve ut Doloplus 2 fordi skjemaet er oversatt til norsk, samt lett å forstå og gjennomføre med litt trening (12). Det er viktig med god smertebehandling uavhengig av kognitiv funksjon. Undersøkelser har vist at smerterelaterte forhold er felles for alle, og at smerte er undervurdert hos pasienter med kognitiv svikt (13). Doloplus 2 er basert på observasjoner av pasientatferd i ti ulike situasjoner som kan avsløre smerte; somatiske, psykomotoriske og psykososiale reaksjoner på smerte. Kartleggingsskjemaet er testet ut i tre ulike studier på sykehjemspasienter i Norge, med ulikt resultat $(4,9,10)$.

\section{Utprøving}

Prøveperioden varte fra våren 2011 til januar 2012. Pasientene ble informert og forespurt om de ville være med og prøve ut smertekartleggingsverktøyene. Pasienter og helsepersonell kunne skrive egne kommentarer på smertekartleggingsverktøyene, for eksempel problemer med bruk av verktøyet, smertestillende medikamenter, nye tiltak og så videre. Prosjektgruppen var selv aktiv i utprøvingen for å skaffe seg erfaring med bruk av skjemaene. Utprøvingen viste at skjemaene var brukervennlige, samt enkle å forstå og fylle ut.

De fleste pasientene som var med på utprøvingen var i stand til selv å rapportere smerte. Når det gjelder palliative pasienter erfarte vi at det var viktig å ta i bruk kartleggingsverktøyet i en tidlig fase av sykdommen, før pasientene ble for dårlige. Helsepersonell opplevde at det var vanskelig å lære opp pasienter i livets sluttfase og kartlegge smerte. I tillegg følte noen at det ble et etisk problem å bruke tid på kartlegging $\mathrm{i}$ stedet for direkte hjelp til smertelindring.

\section{Ba om hjelp}

Noen pasienter hadde problemer med å sette tall på smertene og ba derfor om hjelp til dette. Smerte er en subjektiv opplevelse, og ingen andre enn den som kjenner smerten kan i prinsippet tallfeste den. Helsearbeidere må derfor bruke andre verktøy og veilede pasientene i hvordan de kan tallfeste opplevd smerte (1). Det ble også diskutert om helsepersonellet burde læres opp til å veilede pasienter så likt som mulig eller tilrettelegge arbeidet slik at samme person kunne kartlegge samme pasient over tid. Dette vil vi diskutere videre.

Legene var i utgangspunktet skeptiske til å innføre smertekartleggingsverktøy. De mente det kunne føre til økt bruk av smertestillende medikamenter. For å kunne si noe om dette må man bruke kartleggingsverktøyet i kommunen over en lengre periode. Under utprøvingsperioden kom det forespørsel fra en lege om å prøve ut selvrapporteringsverktøy på en pasient hvor 
man var svært usikre på personens smerteopplevelse. Det var ønskelig at kartleggingen ble gjort i forkant av legetimen. Dette sparte tid for legen og ga vedkommende et bedre og bredere bilde av pasientens smerte som legen kunne bruke til videre utredning og behandling.

\section{Mer helhetlig}

Det ble valgt ut åtte pasienter med ulike smertebilder i samarbeid med tilsynslege eller fastlege til utprøving av de valgte smertekartleggingsverktøyene. I tillegg til smerte kartla ESAS andre plager som ofte opptrer samtidig med smerte. Helsepersonellet opplevde at de fikk kartlagt pasienten bedre med ESAS enn med bare et enkelt smertekartleggingsskjema, fordi pasientens plager var sammensatte. Ved hjelp av ESAS fikk de et mer helhetlig bilde av pasientens opplevelse og kunne gi bedre behandling.

Erfaringen med bruk av smertejournal var god. Den ga ansatte et godt bilde av pasientens smerte, men kartla ikke symptomer som for eksempel kvalme eller trøtthet som ofte opptrer samtidig med smerte. Mange opplevde kroppskartet i smertejournalen som nyttig, og en avdeling for personer med demens prøvde kroppskartet på flere pasienter. De fikk god erfaring med dette og syntes det var et nyttig hjelpemiddel både for pasienter som selv kunne rapportere smerte og de som ikke kunne.

\section{Implementering}

Helseregion Vest gjennomførte et utviklingsprosjekt (2001-2006) om systematisk registrering av symptomer hos pasienter med behov for lindrende behandling, ved hjelp av ESAS. Dette prosjektet viste at det var mulig å innføre systematisk symptomregistrering i et større geografisk område, men at prosessen krevde tid, motivasjon, systematisk oppfølging og gjentatt informasjon og undervisning (13).

\section{«Erfaringen med bruk av smertejournal var god.»}

Åfjord kommune bruker dokumentasjonssystemet Profil og ønsker å få til en god smertedokumentasjon på grunnlag av kartleggingsskjemaene direkte inn i dokumentasjonssystemet Profil. Vi jobber for tiden med dette. Når prosjektperioden er ferdig kan det være en viss fare for at bruken av smertekartleggingsverktøy reduseres fordi man anser det som merarbeid og tungvint. En løsning kan være å bruke små håndholdte datamaskiner og legge inn resultatene fra smertekartleggingen på disse. De kan være enklere å bruke både på sykehjemsavdelinger og i hjemmetjenesten og kan føre til økt bruk av smertekartleggingsverktøy. Ved å legge data direkte inn på en håndholdt computer, slipper man et ekstra mellomledd ved at man først må skrive dataene manuelt og deretter legge dem inn i datamaskinen.

En fordel med dette prosjektet har vært forankringen i utviklingssentret for hjemmetjenester i Sør-Trøndelag. Åfjord har inkludert både hjemmetjenesten og sykehjemmet i utviklingssenteret som har støttet prosjektet ved å fristille tid for personalet til prosjektarbeidet. Utviklingssentret var i tillegg godt forankret i både kommunens, sykehjemmet og hjemmetjenestens ledelse.

Vi håper at det å innføre et felles system for kartlegging av smerter vil bidra til et felles språk og bedre kommunikasjon mellom ulike faggrupper og pasienten, og mellom de ulike tjenesteområdene i Åfjord kommune.

\section{Avslutning}

Utfordringen framover blir å innføre smertekartleggingsverktøyene i kommunenes kvalitetssystem. I tillegg blir det viktig å endre ansattes holdninger til systematisk bruk av smertekartleggingsverktøy. Ved å integrere verktøyene i kommunens kvalitetssystem, vil kommunens internkontroll kunne fange opp svikt i bruken av smertekartleggingsverktøy. IIII

\section{REFERANSER}

Universitetet i Nord-Norge (2012). Håndboki Lindrende behandling. www.unn (Lastetned: 26.03.2013)

2. Kaasa S. Palliasjon. Nordisk lærebok. Oslo: Gyldendal Akademiske, 2008.

3. International Association for the Study of Pain, 2008. http://www.iasp-pain. org (Lastet ned 26.03.2013)

4. Torvik K, Kaasa S, Kirkevold $\emptyset$, Rustøen T. Pain in patients living in Norwegian nursing homes. Palliative medicine 2009;23:8-16.

5. Bergh S. Demens og nevropsykiatriske symptomer hos sykehiemspasienter i Nord-Trøndelag. Tidsskr Nor Legeforen 2012;132:1956-9.

6. Forsberg C, Wengström Y. Att göra systematiska litteraturstudier: värdering, analys och presentation av omvårdnadsforskning. Stockholm: Natur och kultur, 2013

7. Universiteteti Nord-Norge. Smertejournal. www.unn (Lastetned: 26.03.2013)

8. Oslo-universitetssykehus. Edmonton Symptom Asessment System (ESAS). http://www.oslo-universitetssykehus.no/omoss/avdelinger/kompetansesenterfor-lindrende-behandling/esas/Sider/side.aspx (Lastet ned: 08.05.2013).

9. Hølen JC, Saltvedt I, Fayers PM, Bjønnes M, Stenseth G, Hval B, Filbet M, Loge $\mathrm{JH}$, Kaasa S. The Norwegian Doloplus-2 a tool for behavioural pain assessment: translation and pilot-validation in nursing home patients with cognitive impairment. Palliat Med 2005;19:411-17.

10. Hølen JC, Saltvedt I, Fayers PM, Hjermstad MJ, Loge JH, Kaasa S. Doloplus-2 a valid tool for behavioural pain assessment? BMC Geriatr 2007;19:7-29.

11. Rodriguez C, McMillanS, Yarandi H. Pain measurement in older adults with head and neck cancer and communication impairments. Cancer Nursing 2004;6:42533.

12. TorvikK, Kaasa S, Kirkevold Ø, Saltvedt I, Hølen JC, Fayers P, Rustøen T. ValidaTorvik K, Kaasa S, Kirkevold $\emptyset$, Saltvedt I, Hølen JC, Fayers P, Rustøen T.Valida-
tion of Doloplus-2 among nonverbal nursing home patients - an evaluation of tion of Doloplus-2 among nonverbal nursing home pa
Doloplus-2 in a clinical setting. BMC Geriatr 2010;0:9.

13. Kompetansesenter ilindrende behandling Helseregion Vest (2006). Systematisk symptomregistrering i lindrende behandling-ved hjelp av ESAS. Et driftsmessig utviklingsprosjekti Helseregion Vest. Rapport.

Fagartikler kan sendes til torhild.apall@sykepleien.no

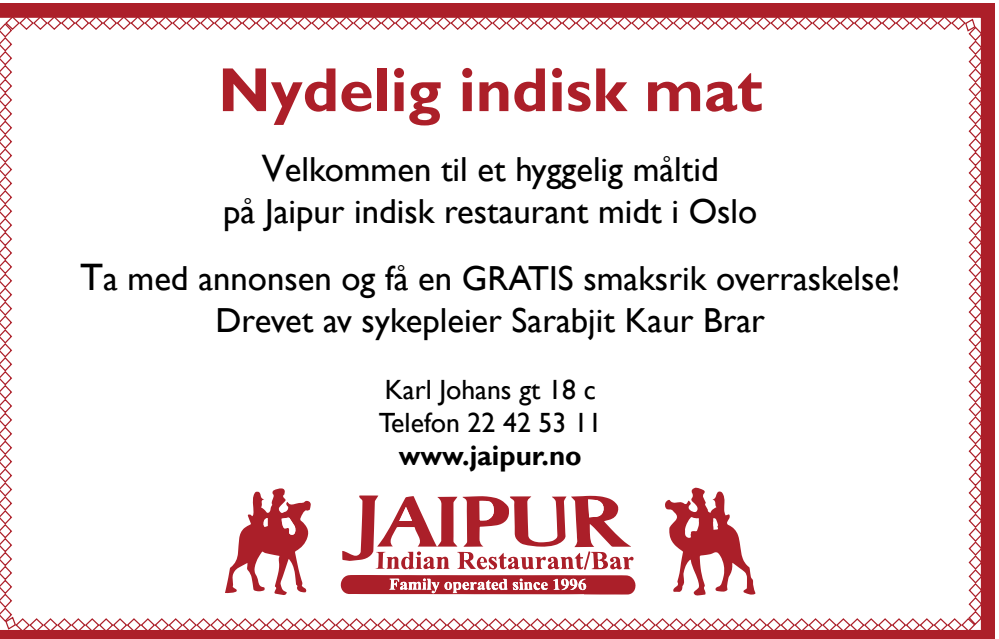

